\title{
UNILATERAL PROPTOSIS OF UNEXPLAINED ORIGIN. IV*†
}

BY

\author{
ALY MORTADA \\ Department of Ophthalmology, Faculty of Medicine, Cairo University, Egypt
}

IN addition to my previous reports (Mortada, 1962, 1963a, 1965), the two following cases of unilateral proptosis due to malignant nasopharyngeal tumours are of interest because both were first diagnosed as "proptosis of unexplained origin", and also because both were in fact due to malignant salivary gland tumours, a type which rarely affects the nasopharynx.

\section{Case Reports}

In the two cases to be described the general condition of the patients was good and a complete systemic examination, including blood tests and the elimination of infective and allergic manifestations, gave normal results. The unilateral proptosis was painless, not intermittent, not pulsating, forward in direction, and moderate in degree (about $20 \mathrm{~mm}$.). The eyes and their fundi were otherwise normal, with no limitation of ocular movements, ptosis, unilateral myopia, or visual deterioration. No orbital mass could be palpated through the lids or conjunctival fornix even under general anaesthesia; nor did exploration by lateral orbitotomy (Knapp, 1874; Reese, 1935) reveal any abnormality.

Case 1, a 15-year-old boy, had left proptosis of $20 \mathrm{~mm}$. when first seen and 3 months later this had increased to $24 \mathrm{~mm}$. (right side $15 \mathrm{~mm}$.) with left 6 th nerve paralysis (Fig. 1). The left fundus was normal and the visual acuity $6 / 18$. The left upper cervical lymph glands were enlarged, fixed, and hard, and he was found to have a nasopharyngeal tumour. A postero-anterior skull $x$ ray (Fig. 2) showed destruction of the left lesser and greater wings of the sphenoid bone with an enlarged superior orbital fissure and an opaque left maxillary antrum. A soft irregular mass was found to be entering the left orbit through the enlarged superior orbital fissure.

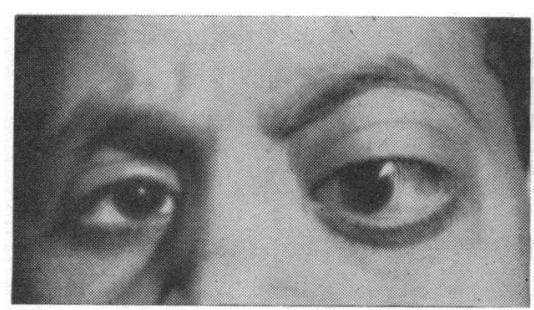

FIG. 1.-Case 1. 3 months after first examination, showing left proptosis and paralysis of the 6th nerve.

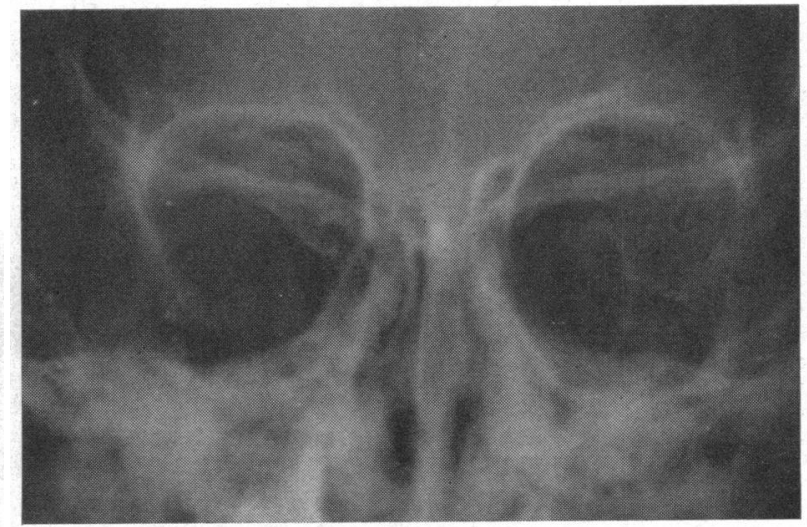

Fig. 2.-Case 1. Skull postero-anterior $x$ ray, showing destruction of the left lesser and greater wings of the sphenoid bone with an enlarged superior orbital fissure and an opaque left maxillary antrum.

* Received for publication December 28, 1966

† Address for reprints: 18A 26 July Street, Cairo, Egypt. 
Histopathological examination of a biopsy specimen showed that this was an adeno-carcinoma (Fig. 3).

Fig. 3. - Case 1. Adenocarcinoma of the nasopharynx. $\times 120$.

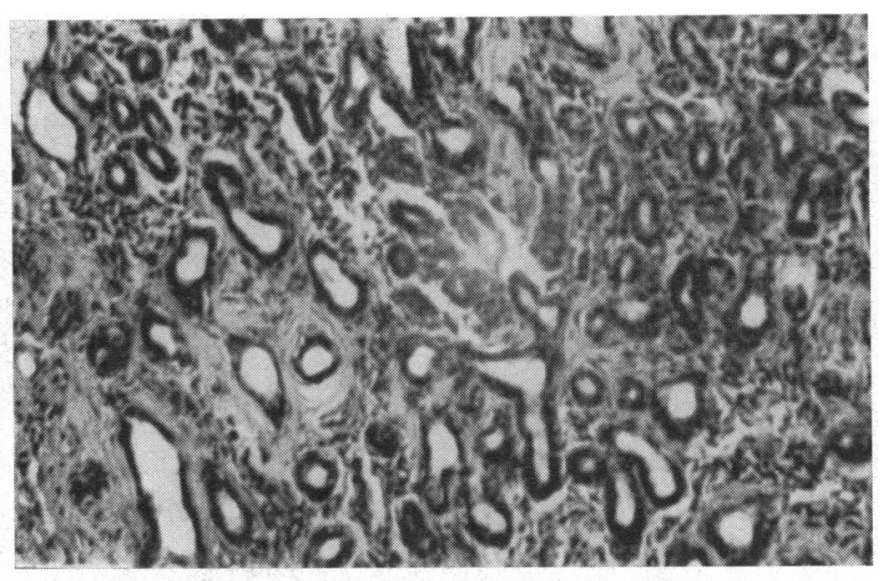

Case 2, a 45-year-old man, had left proptosis of $20 \mathrm{~mm}$. when first seen, and 4 months later the left upper cervical lymph glands were enlarged, fixed, and hard. The right eye was normal with a normal fundus and visual acuity $6 / 9$.

The left eye showed proptosis $23 \mathrm{~mm}$. (right side $16 \mathrm{~mm}$.), total ophthalmoplegia, and optic atrophy; the visual acuity was reduced to $1 / 60$. A postero-anterior skull $x$ ray showed destruction of the left lesser and greater wings of the sphenoid bone and an opaque left maxillary antrum. The base of the skull showed destruction of the basi occiput. The left lateral nasopharyngeal wall showed a dark purple irregular hard mass measuring $2 \times 3 \mathrm{~cm}$., which bled easily on contact. A soft mass was found to be entering the left orbit through the superior orbital fissure. Histopathological examination of a biopsy specimen of this nasopharyngeal tumour showed that it was an adenoid-cystic-carcinoma.

Both patients were given radiotherapy. In spite of improvement after the radiation treatment, both died with recurrence of the nasopharyngeal tumours and toxaemia within 5 years of the onset.

\section{Discussion}

The nasopharyngeal mucous membrane contains not only epithelial and fibro-adenoid layers but also mucous and serous glands, a part of the accessory salivary glands which are also present in the palate, lips, tongue, gums, tonsillar fossa, larynx, trachea, nose, and accessory nasal sinuses. These may give rise to tumours of the same nature as salivary and lacrimal gland epithelial neoplasms, which may take the form of malignant mixed gland tumour, adeno-carcinoma or squamous cell, undifferentiated or adenoid-cysticcarcinoma (Hogan and Zimmerman, 1962). Malignant mixed salivary tumour of the maxillary sinus and adeno-carcinoma and adenoid-cystic-carcinoma of the ethmoid sinuses have been reported by Mortada (1963b).

Histopathological study of my 21 cases of malignant nasopharyngeal tumours causing unilateral proptosis showed two basal cell carcinomata, eight squamous cell carcinomata, three adeno-carcinomata, two adenoid-cystic-carcinomata, five reticulum-cell-sarcomata, and one lymphosarcoma. In three of these cases (one adeno-carcinoma, one adenoidcystic-carcinoma, and one lymphosarcoma of the nasopharynx), the first sign of disease was unilateral proptosis of unexplained origin. Reese (1963), discussing nasopharyngeal tumours and proptosis, stated: 
"In the early stages this tumour may not give rise to any indications of its presence. Due to this difficulty in examining the primary site adequately the first manifestation of the tumour may be some eye symptoms. At a time when the primary site is still quite small even small enough to be overlooked (especially when it is in the fossa of Rosenmüller) the tumour may already have reached the orbit and produced ocular symptoms. For this reason patients with nasopharyngeal tumours sometimes first consult the ophthalmologist who should therefore keep in mind the possibility of latent nasopharyngeal tumours".

\section{Summary}

(1) Unilateral proptosis of unexplained origin may be caused by malignant nasopharyngeal tumours in the earliest stages.

(2) These are the first two cases of adeno-carcinoma and adenoid-cystic-carcinoma of the nasopharynx causing unilateral proptosis of unexplained origin to be reported from Egypt.

\section{REFERENCES}

Hogan, M. J., and Zimmerman, L. E. (1962). "Ophthalmic Pathology", 2nd ed., p. 758. Saunders, Philadelphia.

Knapp, H. (1874). Klin. Mbl. Augenheilk., 12, 439.

MORTADA, A. (1962). Brit. J. Ophthal., 46, 369.

(1963a). Ibid., 47, 445 .

(1963b). Ibid., 47, 279.

(1965). Ibid., 49, 547.

ReEse, A. B. (1935). Arch. Ophthal. (Chicago), 14, 41.

(1963). "Tumors of the Eye", 2nd ed., p. 543. Harper and Row, New York, Evanston, and London. 